MATEC Web of Conferences 42, 04002 (2016)

DOI: $10.1051 /$ matecconf/20164204002

(C) Owned by the authors, published by EDP Sciences, 2016

\title{
Adaptive $\mathrm{NO}_{\mathrm{x}}$ Soft Sensor for Aftertreatment of Diesel Engines
}

\author{
Shinichi Ishizuka ${ }^{1, a}$, Itsuro Kajiwara ${ }^{1}$, Junichi Sato ${ }^{2}$, Yoshifumi Hanamura ${ }^{2}$ \\ ${ }^{1}$ Hokkaido University in St. Louis, Japan \\ 2 ISUZU Motors Limited, Japan
}

\begin{abstract}
As environmental regulations become stricter, diesel engines must become cleaner. Hence, in addition to combustion control, aftertreatment of the exhaust is important to reduce emissions involving $\mathrm{NO}_{\mathrm{X}}$ and diesel particulate matter (DPM). $\mathrm{NO}_{\mathrm{X}}$ is eliminated by a chemical reaction with ammonia, which is generated by hydrolysis of injected urea. Although the $\mathrm{NO}_{\mathrm{X}}$ concentration must be accurately detected to ensure the appropriate quantity of urea is used, the response speed of the current $\mathrm{NO}_{\mathrm{X}}$ sensor is too slow to follow transient operations. In this paper, a new $\mathrm{NO}_{\mathrm{X}}$ adaptive soft sensor for aftertreatment of diesel engines is described, and its basic characteristics are confirmed via an engine bench test.
\end{abstract}

\section{Introduction}

Diesel engines are becoming cleaner in order to adapt to the increasingly stringent environmental requirements. Both combustion control and aftertreatment of the exhaust are critical to reduce emissions involving $\mathrm{NO}_{\mathrm{X}}$ and diesel particulate matter (DPM). $\mathrm{NO}_{\mathrm{X}}$ is eliminated via a chemical reaction with ammonia, which is generated by hydrolysis of urea. To adequately control the urea concentration, the $\mathrm{NO}_{\mathrm{X}}$ concentration must be precisely measured. Because the response speed of the typical $\mathrm{NO}_{\mathrm{X}}$ sensor is insufficient to follow transient operations, the $\mathrm{NO}_{\mathrm{X}}$ concentration is estimated by a soft sensor, which calculates the variables that affect $\mathrm{NO}_{\mathrm{X}}$. However, the calculated and actual $\mathrm{NO}_{\mathrm{X}}$ concentrations may differ. In this paper, an overview of the aftertreatment of diesel engines is provided at first. Then our adaptive soft sensor is described. Finally, the basic characteristics of the proposed sensor are confirmed via a bench experiment.

\section{Aftertreatment of a diesel engine}

Figure 1 shows the aftertreatment system of a diesel engine where blue and red indicate the air intake and exhaust systems, respectively. DPM is trapped and accumulated by a diesel particulate filter (DPF) and can be burned off when the accumulation reaches a certain level. $\mathrm{NO}_{\mathrm{X}}$ is decomposed into water and nitrogen by selective catalytic reduction (SCR) at the appropriate temperature to accelerate the chemical reaction. In SCR, urea is injected and is subsequently hydrolyzed into ammonia and carbon dioxide. The ammonia then renders NOx harmless by reducing it to water and nitrogen via the following chemical reactions

\footnotetext{
$\overline{{ }^{a} \text { Corresponding author: ishizuka@ }}$ cybernet.co.jp
}

$$
\begin{aligned}
& \left(\mathrm{NH}_{2}\right) 2 \mathrm{CO}+\mathrm{H}_{2} \mathrm{O} \rightarrow 2 \mathrm{NH}_{3}+\mathrm{CO}_{2} \\
& \mathrm{NO}+\mathrm{NO}_{2}+2 \mathrm{NH}_{3} \rightarrow 2 \mathrm{~N}_{2}+3 \mathrm{H}_{2} \mathrm{O}
\end{aligned}
$$

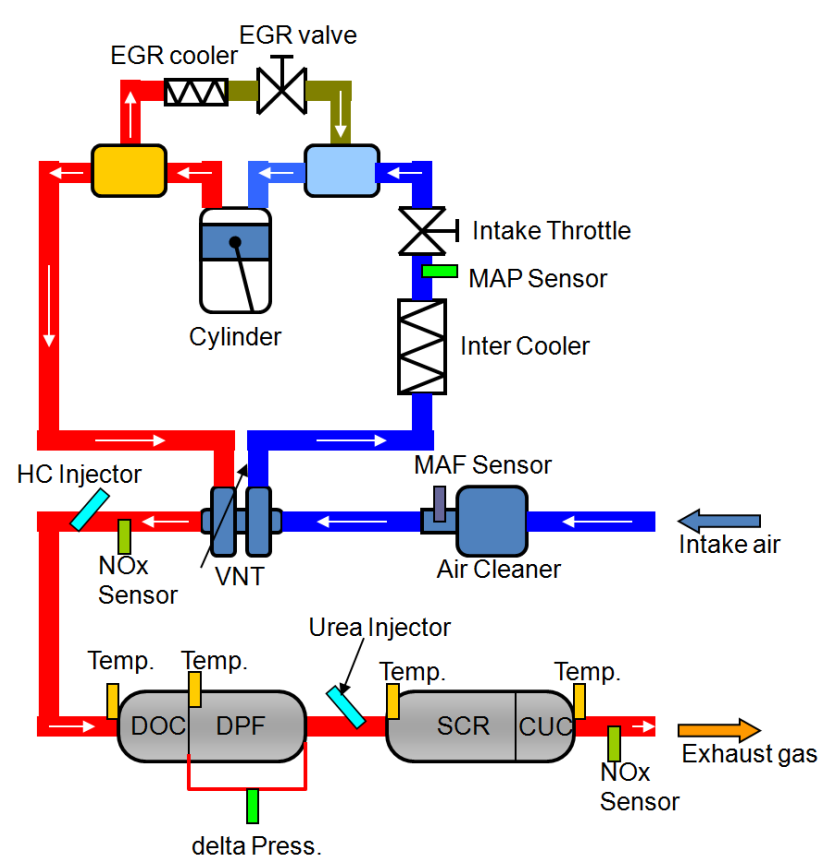

Figure 1. Aftertreatment system of a diesel engine.

The amount of injected urea must be controlled to correspond to the $\mathrm{NO}_{\mathrm{X}}$ concentration. An insufficient urea concentration results in incomplete $\mathrm{NO}_{\mathrm{X}}$ processing, whereas too much urea causes harmful ammonia to leak to the outside. Because the $\mathrm{NO}_{\mathrm{X}}$ sensor response is too slow to detect the $\mathrm{NO}_{\mathrm{X}}$ concentration transiently, it is estimated by a calculation. Herein a $\mathrm{NO}_{\mathrm{X}}$ sensor device that measures the actual $\mathrm{NO}_{\mathrm{X}}$ concentration is a called a 
"NO $\mathrm{X}_{\mathrm{X}}$ hard sensor", while a sensor that calculates the $\mathrm{NO}_{X}$ concentration from other factors is called a "NO soft sensor". In the conventional method, a $\mathrm{NO}_{\mathrm{X}}$ hard sensor is used during stationary operations, but it is switched to a $\mathrm{NO}_{\mathrm{X}}$ soft sensor during transient operations. In this paper, an adaptive $\mathrm{NO}_{\mathrm{X}}$ soft sensor method, which is compensated by a $\mathrm{NO}_{\mathrm{X}}$ hard sensor, is proposed.

\section{$3 \mathrm{NO}_{\mathrm{x}}$ soft sensor}

\subsection{Basic composition}

A typical soft sensor employs either a just-in-time model [1] or a neural network-based [2] method. However, these methods are not model based and the factors that influence $\mathrm{NO}_{\mathrm{X}}$ are indistinct. From the viewpoint of practical calibrations, a soft sensor should be structured so that the effect of each factor can be tuned independently and simultaneously. In this study, an experiment-based soft sensor model is used. Figure 2 shows the $\mathrm{NO}_{\mathrm{X}}$ soft sensor scheme where the dashed red and solid blue lines denote parameters and variables, respectively. The $\mathrm{NO}_{\mathrm{X}}$ soft sensor calculates the $\mathrm{NO}_{\mathrm{X}}$ concentration as shown in Equation 2:

$$
\psi_{\mathrm{NOx}}=\psi_{\mathrm{NOx}, \mathrm{ref}} \cdot C_{\mathrm{O} 2} \cdot C_{\mathrm{SOI}} \cdot C_{R P} \cdot C_{\text {Tcool }} \cdot C_{\text {Tinm }}
$$

where $\psi_{N O x}$ is the $\mathrm{NO}_{\mathrm{X}}$ concentration as a mole fraction. The terms on the right-hand side affect $\mathrm{NO}_{\mathrm{X}}$, and the subscripts denote
O2: $\mathrm{O}_{2}$ concentration

SOI: Main injection timing

$R P: \quad$ Rail pressure

Tcool: Temperature of the cooling water

Tinm: Temperature of the intake manifold

Each term is described as

$$
\left\{\begin{array}{l}
C_{O 2}=\left(\frac{\psi_{O 2, c y l}}{\psi_{O 2, c y l, r e f}}\right)^{\alpha_{O 2}} \\
C_{S O I}=e^{\alpha_{S O I} \cdot\left(\theta_{S O I}-\theta_{S O I, r e f}\right)} \\
C_{R P}=\left\{\alpha_{R P} \cdot\left(p_{\text {rail }}-p_{\text {rail }, \text { ref }}\right)+1\right\} \\
C_{\text {Tcool }}=\left\{\alpha_{\text {Tcool }} \cdot\left(T_{\text {cool }}-T_{\text {cool }, \text { ref }}\right)+1\right\} \\
C_{\text {Tinm }}=\left(\frac{T_{\text {inm }}}{T_{\text {inm }, \text { ref }}}\right)^{\alpha_{\text {Tinm }}}
\end{array}\right.
$$

In Equations (1) and (2), the variables with subscript the ref denote the nominal values under normal atmospheric conditions, while the variables with $a_{*}$ indicate calibration factors when the operation condition differs from the standard condition (i.e., the variable does not affect the calculated value when the state is the same as the normal condition). Each nominal value (,ref) and calibration factor $\left(a_{*}\right)$ can be plotted to form a 2D map using engine speed and fuel injection quantity as the parameters.

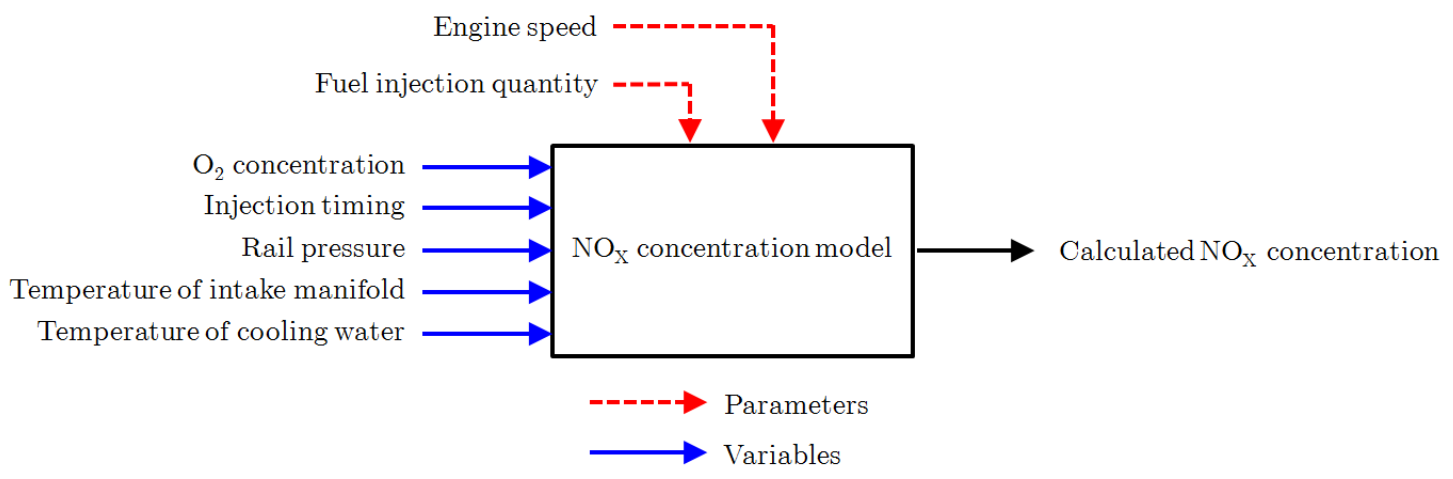

Figure 2. Scheme of the $\mathrm{NO}_{\mathrm{X}}$ soft sensor.

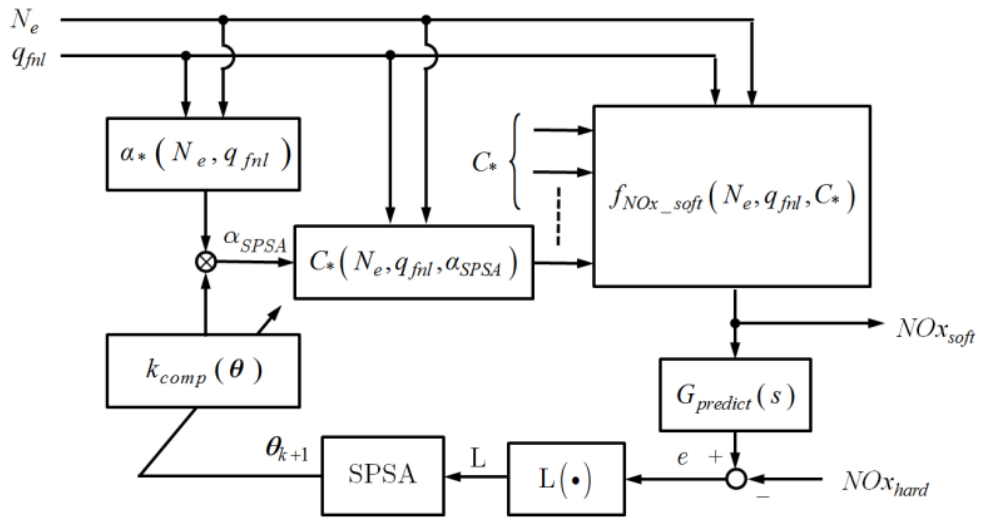

Figure 3. Composition of the adaptive $\mathrm{NO}_{\mathrm{X}}$ soft sensor. 


\subsection{Adaptive $\mathrm{NO}_{\mathrm{x}}$ soft sensor}

To eliminate the offset in a $\mathrm{NO}_{\mathrm{X}}$ soft sensor, the gain of the offset is compensated compared with the $\mathrm{NO}_{\mathrm{X}}$ hard sensor value. Figure 3 diagrams the proposed adaptive $\mathrm{NO}_{\mathrm{X}}$ soft sensor. SPSA stands for the simultaneous perturbation stochastic approximation, which was originally proposed by Spall in 1987 [3] as a very efficient optimization technique. An online adaptive tuning method using a modified SPSA is proposed by the authors [4], [5]. In this study, our modified SPSA is utilized. The $\mathrm{NO}_{\mathrm{X}}$ soft sensor value $N O x_{\text {soft }}$ is derived from predictor $G_{\text {predict }}$, which predicts the behavior of the $\mathrm{NO}_{\mathrm{X}}$ hard sensor dynamics. $G_{\text {predict }}$ is calculated from loss function $L$ and modified gain $k_{\text {comp }}$. Each term $C_{*}$ is tuned simultaneously and continuously by the modified SPSA.

\subsection{SPSA algorithm}

The modified SPSA is briefly described here. For more details, refer to [4]. The estimated value of the loss function gradient is expressed as

$$
\hat{\theta}_{k+1}=\hat{\theta}_{k}-a_{k} \hat{\mathrm{g}}_{k}\left(\hat{\theta}_{k}\right)
$$

where $\hat{\theta}_{k}$ is the estimated optimization parameter vector, $a_{k}$ is the update gain, and $\hat{\mathrm{g}}_{k}\left(\hat{\theta}_{k}\right)$ is the estimated value of the gradient for the parameter, which is described as

$$
\hat{\mathrm{g}}_{k} \hat{\theta}_{k}=\frac{L \hat{\theta}_{k}+c_{k} \triangle_{k}}{c_{k}}\left\{\begin{array}{c}
\triangle_{k 1}^{-1} \\
\triangle_{k 2}^{-1} \\
\vdots \\
\triangle_{k p}^{-1}
\end{array}\right\}
$$

where $L$ is the loss function, $c_{k}$ is a coefficient with a minute positive value to adjust the perturbation, and $\Delta_{k}$ is a bounded $p$-dimensional random number vector with a symmetric distribution when the expected value is 0 and no element can ever be zero (e.g., a Bernoulli distribution). For example, Equation (6) shows a random number vector expressed as a random binary sequence

$$
\Delta_{k}=\left\{\begin{array}{llllllll}
1, & -1, & -1, & 1, & -1, & 1, & 1, & \cdots
\end{array}\right\}^{T}
$$

By choosing $a_{k}$ and $c_{k}$ appropriately and iterating Equation (4) recursively, the estimated optimal parameters converge to an optimal value as a stationary system. The standard SPSA evaluates the loss function twice by perturbing all the tuning parameters simultaneously. In this case, a one-time evaluation SPSA [6] is used. The sum of the squared error is used as the loss function.

\section{Experiment}

\subsection{Engine bench}

The adaptive $\mathrm{NO}_{\mathrm{X}}$ soft sensor algorithm was modeled with Simulink and downloaded to a rapid controller prototyping environment. The diesel engine was for a medium truck with a displacement of about $5,200 \mathrm{cc}$. Table 1 shows the specifications, and Figure 4 shows the engine bench. In Equqtion (3), the nominal variables with the $r e f$ subscript and calibration variables $a_{*}$ are tuned for the experimental engine. Generally, an engine's characteristics change during operation and due to aging. To reproduce these situations, each calibration map changes 1.5 times (i.e., the calibration map contains some errors and the operation conditions are altered as shown in Table 2).

Table 1. Engine specifications.

\begin{tabular}{|c|c|}
\hline \hline Type & Direct injection, DOHC, IC turbo \\
\hline \hline Displacement & $5193 \mathrm{cc}$ \\
\hline Compression ratio & 15.5 \\
\hline Maximum power & $140 \mathrm{~kW} / 2600 \mathrm{rpm}$ \\
\hline Maximum torque & $510 \mathrm{Nm} / 1600 \mathrm{rpm}$ \\
\hline Regulation & Euro 6 \\
\hline \hline
\end{tabular}

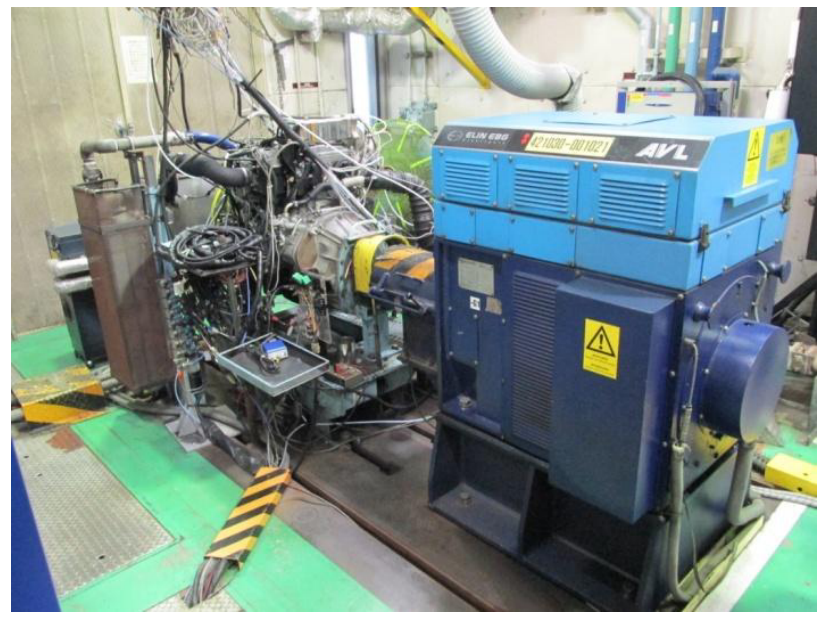

Figure 4. Engine bench.

Table 2. Operation conditions

\begin{tabular}{|c|c|}
\hline \hline Changing item & Notes \\
\hline \hline EGR valve & Half of the nominal amount \\
\hline Injection timing & 2 degree retard of the crank angle \\
\hline Rail pressure & $-30 \mathrm{MPa}$ \\
\hline \hline
\end{tabular}

\subsection{Test pattern}

The test was carried out at the middle and high engine speed points while changing the amount of fuel injection such that the load was changed stepwise. The upper plot in Figure 5 shows the test pattern. The blue and green lines indicate the engine speed trace and the change in the amount of fuel injection, respectively.

The lower plot in Figure 5 shows the $\mathrm{NO}_{\mathrm{X}}$ concentration where black, green, blue, and red lines indicate the values measured by a hard sensor, a soft sensor without 
calibration map error, a soft sensor with calibration map error, and an adaptive soft sensor with calibration map error. To make a direct comparison of the hard and soft sensors, the dynamics of each soft sensor response is compensated by the hard sensor delay. In the case of the soft sensor with calibration map error, the value deviates significantly from the hard sensor. Although the error is slightly smaller in the case of the soft sensor without calibration map error, the error is still large. However, the proposed adaptive soft sensor can adapt to appropriately reduce the error.
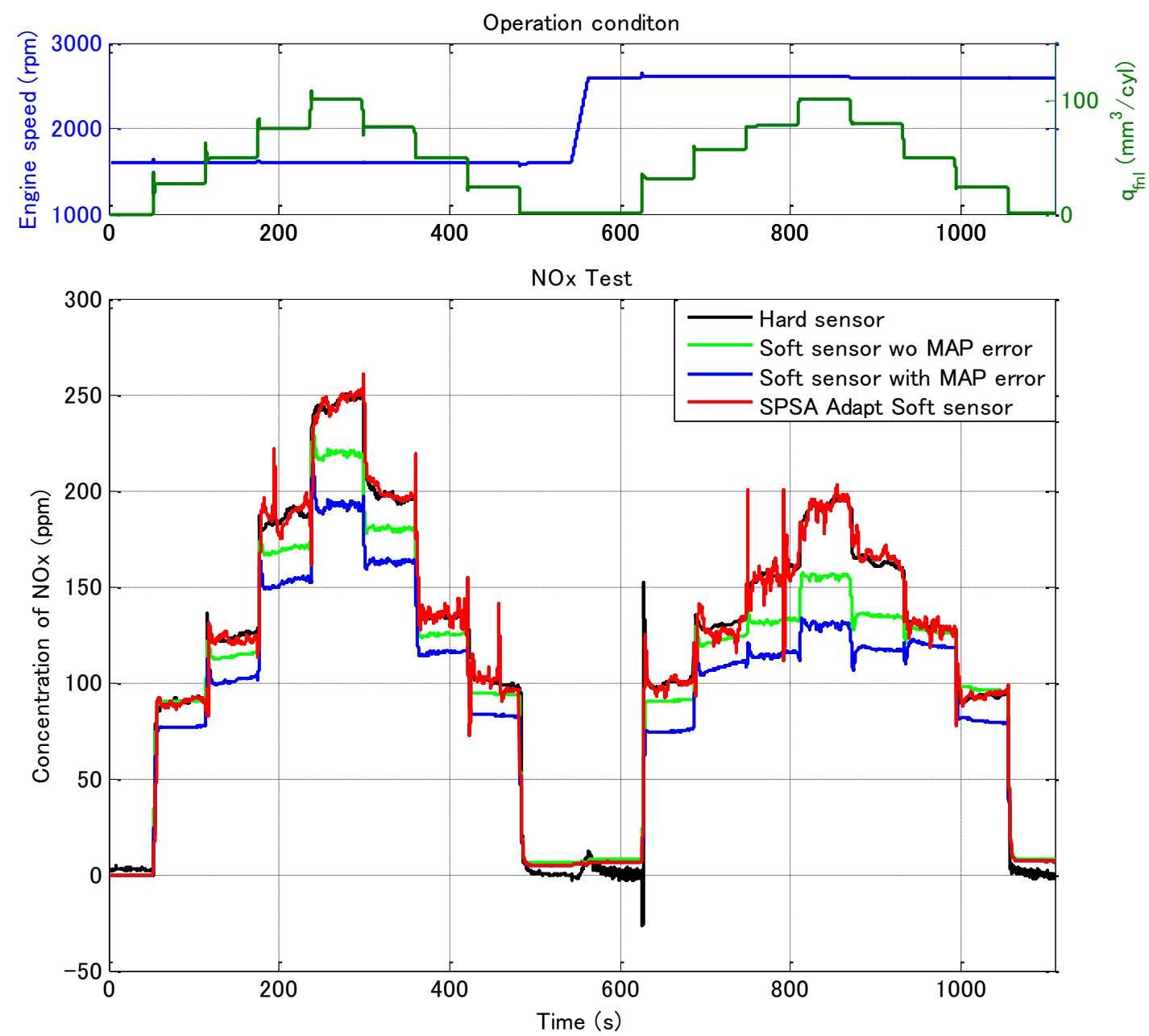

Figure $5 . \mathrm{NO}_{\mathrm{X}}$ test results.

\section{Summary}

This study investigates the use of $\mathrm{NO}_{\mathrm{X}}$ soft sensors in the aftertreatment of diesel engines. To eliminate the offset from the $\mathrm{NO}_{\mathrm{X}}$ hard sensor, an adaptive $\mathrm{NO}_{\mathrm{X}}$ soft sensor using SPSA is proposed. The most distinctive feature of the SPSA algorithm is that the calculation only requires that the loss function be determined once or twice per iteration regardless of the number of optimization parameters. In this study, the soft sensor model has five calibration terms, which are simultaneously updated and tuned using SPSA. The adaptability of the proposed method is confirmed using a stepwise engine bench test. Even if the condition differs significantly from the standard condition, the proposed method adapts appropriately. In the future, it is planned to investigate the proposed method under transient conditions like a world harmonized transient cycle (WHTC).

\section{References}

1. A. Saptoro, State of the Art in the Development of Adaptive Soft Sensors based on Just-In-Time Models, Procedia Chemistry, Vol. 9, pp. 226-234 (2014).

2. M. Shakil, M. Elshafei, M. A. Habib and F. A. Maleki, Soft sonsor for $\mathrm{NO}_{\mathrm{X}}$ and $\mathrm{O}_{2}$ using dynamic neural networks, Computers and Electrical Engineering, Vol. 35, pp. 578-586 (2009).

3. J. C. Spall, A STOCHASTIC APPROXIMATION TECHNIQUE FOR GENERATING MAXIMUM LIKELIHOOD PARAMETER ESTIMATTES, Proceedings of the American Control Conference, Minneapolis, MN, pp. 1161-1167 (1987).

4. S. Ishizuka and I. Kajiwara, Online adaptive PID control for MIMO systems using simultaneous perturbation stochastic approximation, JSME Journal of Advanced Mechanical Design, Systems, and Manufacturing, Vol. 9, No. 2 (2015). 
5. S. Ishizuka, I. Kajiwara, J. Sato, Y. Hanamura and S. Hanawa, Model-free adaptive control scheme for EGR/VNT control of a diesel engine using the simultaneous perturbation stochastic approximation, SAGE Transactions of the Institute of Measurement and Control, Online fist published on Sept. 4 (2015), http://tim.sagepub.com/content/early/2015/08/28/014 2331215602327.abstract

6. J. C. Spall, A One-measurement Form of Simultaneous Perturbation Stochastic Approximation, Automatica, Vol. 33, No. 1, pp. 109-112 (1997). 